\title{
Clinical Performance of New Software to Automatically Detect Angioectasias in Small Bowel Capsule Endoscopy
}

\author{
Dalila Costa $^{a-c}$ Pedro Vieira $^{d}$ Catarina Pinto $^{a}$ Bruno Arroja $^{c}$ Tiago Leal ${ }^{c}$ \\ Sofia Mendes ${ }^{a-c}$ Raquel Gonçalves ${ }^{c}$ Carlos Lima $^{d}$ Carla Rolanda $^{a-c}$ \\ aLife and Health Sciences Research Institute (ICVS), School of Medicine, University of Minho, Braga, Portugal; \\ bICVS/3B's, PT Government Associate Laboratory, Guimarães/Braga, Portugal; 'Gastroenterology Department, \\ Braga Hospital, Braga, Portugal; ${ }^{d}$ CMEMS-Uminho Research Unit, University of Minho, Guimarães, Portugal
}

\section{Keywords}

Video capsule endoscopy · Angioectasias · Automatic detection · Algorithm

\section{Abstract}

Background: Video capsule endoscopy (VCE) revolutionized the diagnosis and management of obscure gastrointestinal bleeding, though the rate of detection of small bowel lesions by the physician is still disappointing. Our group developed a novel algorithm (CMEMS-Uminho) to automatically detect angioectasias which display greater accuracy in VCE static frames than other methods previously published. We aimed to evaluate the algorithm overall performance and assess its diagnostic yield and usability in clinical practice. Methods: Algorithm overall performance was determined using 54 full-length VCE recordings. To assess its diagnostic yield and usability in clinical practice, 38 VCE examinations with the clinical diagnosis of angioectasias consecutively performed (2017-2018) were evaluated by three physicians with different experiences. The CMEMS-Uminho algorithm was also applied. The performance of the CMEMS-Uminho algorithm was defined by a positive concordance between a frame automatically selected by the software and a study indepen-
(C) 2020 Sociedade Portuguesa de Gastrenterologia Published by S. Karger AG, Basel

This article is licensed under the Creative Commons AttributionNonCommercial-NoDerivatives 4.0 International License (CC BYNC-ND) (http://www.karger.com/Services/OpenAccessLicense). Usage and distribution for commercial purposes as well as any distribution of modified material requires written permission. dent capsule endoscopist. Results: Overall performance in complete VCE recordings was $77.7 \%$, and diagnostic yield was $94.7 \%$. There were significant differences between physicians in regard to global detection rate $(p<0.001)$, detection rate per capsule $(p<0.001)$, diagnostic yield $(p=0.007)$, true positive rate $(p<0.001)$, time $(p<0.001)$, and speed viewing $(p<0.001)$. The application of CMEMS-Uminho algorithm significantly enhanced all readers' global detection rate $(p<0.001)$ and the differences between them were no longer observed. Conclusion: The CMEMS-Uminho algorithm detained a good overall performance and was able to enhance physicians' performance, suggesting a potential usability of this tool in clinical practice.

\footnotetext{
(C) 2020 Sociedade Portuguesa de Gastrenterologia Published by S. Karger AG, Basel
}

\section{Performance clínica de um novo software para detetar automaticamente angiectasias na endoscopia por cápsula}

\section{Palavras Chave \\ Endoscopia por cápsula · Angiectasias · Deteção automática $\cdot$ Algoritmo}

\section{Dalila Costa}

Gastroenterology Department, Braga Hospital

Sete Fontes - São Victor

PT-4710 Braga (Portugal)

dc.dalilacosta@gmail.com 


\section{Resumo}

Introdução: A endoscopia por cápsula (EC) revolucionou o diagnóstico da hemorragia gastrointestinal obscura, porém a taxa de deteção de lesões no intestino delgado pelo endoscopista permanece insatisfatória. Desenvolveu-se um novo algoritmo para a deteção automática de angioectasias, que revelou uma melhor acuidade na avaliação de imagens de EC que outros métodos previamente publicados. Pretende-se avaliar agora a performance global do algoritmo, o seu rendimento diagnóstico e a utilidade na prática clínica. Métodos: A performance global do algoritmo foi avaliada com 54 vídeos de EC. Para avaliar o seu rendimento diagnóstico e utilidade na prática clínica, 38 EC consecutivas com diagnóstico clínico de angiectasias (2017-2018) foram analisadas por três médicos com experiência distinta. A performance do algoritmo CMEMS-Uminho foi definida por uma concordância positiva entre um frame selecionado automaticamente pelo software e um endoscopista de cápsula independente do estudo. Resultados: O algoritmo CMEMS-Uminho revelou uma performance global de 77,7\% e um rendimento diagnóstico de $94,7 \%$. Os médicos apresentaram diferenças significativas na taxa de deteção global $(p<0,001)$, taxa de deteção por cápsula ( $p<0,001)$, rendimento diagnóstico $(p=0,007)$, taxa de verdadeiros positivos $(p<0,001)$, tempo $(p<0,001)$ e velocidade de visualização $(p<0,001)$. A aplicação do algoritmo CMEMS-Uminho melhorou significativamente a taxa de deteção dos médicos $(p<0,001)$ e as diferenças entre eles diluiram-se após a sua aplicação. Conclusão: $\mathrm{O}$ algoritmo CMEMS-Uminho deteve um bom desempenho global e foi capaz de melhorar o desempenho médico, sugerindo uma potencial utilidade desta ferramenta na prática clínica.

() 2020 Sociedade Portuguesa de Gastrenterologia Published by S. Karger AG, Basel

\section{Background}

Video capsule endoscopy (VCE) appears as a reliable, safe, and non-invasive diagnostic method [1], which revolutionized the definition, diagnosis, and management of obscure gastrointestinal bleeding (OGIB) [2-4]. This method consists in swallowing a non-reusable wireless capsule with a miniaturized camera that travels through the gastrointestinal tract. The camera captures 50,00060,000 images, uploaded in a video with about $8-12 \mathrm{~h} \mathrm{[5}$, 6]. All endoscopic capsules developed so far have similar components, but each individual VCE system has distinct specifications such as resolution and image capture, transmission, and video duration $[7,8]$. There is no agreement in the literature about the best system, so the choice of VCE software depends on the operator/institution.

Despite the contribution to the diagnosis of small bowel (SB) diseases (OGIB, Crohn's disease or familial polyposis syndromes) $[2-4,9]$, VCE has several limitations: absence of movement and camera orientation control, which allows blind SB areas, difficulty in locating lesions within SB, lack of specificity, inability to perform endoscopic therapy, and image interpretation is physician dependent $[8,10]$. There is great heterogeneity concerning image reading, namely in the mode and speed of visualization $[6,11]$. It takes $45-90 \mathrm{~min}$ to evaluate a VCE, and studies show that faster readings decrease the detection rate [6]. To date, there is no gold standard method, contributing to interobserver variability.

Digestive hemorrhage from the SB occurs with an estimated prevalence of 5-10\% [3]. For OGIB, diagnostic yield for VCE ranges between 38 and 83\% [12]. The most prevalent etiology in patients older than 40 years is angioectasias [3]. These degenerative lesions of previously healthy blood vessels account for up to $8 \%$ of all episodes of gastrointestinal tract bleeding [13]. Zheng et al. [6] revealed a disappointing detection rate of angioectasias by physicians. Though only $69 \%$ of angioectasias were detected, this value was significantly higher than for other SB lesions.

Computational methods have been implemented in the reviewing software of the VCE devices to improve diagnostic yield and time efficiency [14].

Most commercially available tools are integrated in the RAPID reader workstation (Given Imaging ${ }^{\circledR}$ ). One of the first methods developed was suspected blood indicator, which has been criticized for its suboptimal performance, even for patients with active intestinal bleeding [15-16]. VCE technology has been further expanded with the incorporation of Flexible Spectral Imaging Color Enhancement (FICE) and the Blue Filter (BF) modes [17]. However, it is currently controversial whether virtual chromoendoscopy may increase the diagnostic accuracy of VCE [18]. TOP100, which automatically select 100 frames of interest, was incorporated in the late version of RAPID ${ }^{\circledR}$ software. For an overall detection of significant lesions, TOP 100 identified $76.3 \%$ lesions with a sensitivity of $51.28 \%$ [19]. Despite recent improvements, these methods still display limitations.

Regarding MiroCam ${ }^{\circledR}$ software (IntroMedic, Korea), studies are scarce, and the tools are limited. The Augmented Live-Body Image Color-Spectrum Enhancement (ALICE) chromoendoscopy system was able to enhance
88

GE Port J Gastroenterol 2021;28:87-96 DOI: $10.1159 / 000510024$
Costa/Vieira/Pinto/Arroja/Leal/Mendes/ Gonçalves/Lima/Rolanda 
Fig. 1. Original frames of angioectasias with different diameters (above) and the component a of the same lesions (below).

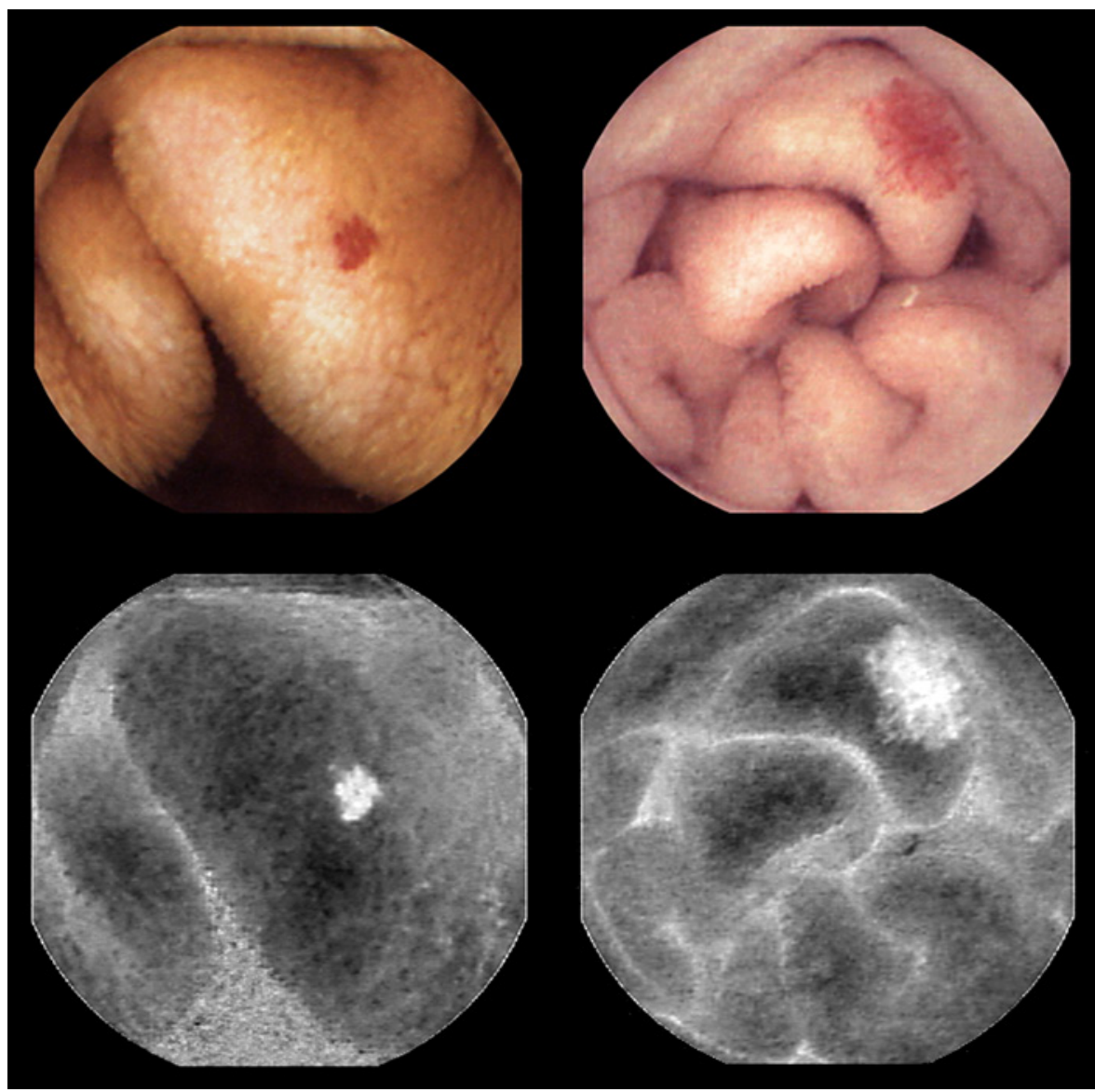

the visibility of angioectasias [20]. On contrary, another chromoendoscopy system that enhances the image in 3 color modes (CM1, CM2, and CM3) was not useful to improve evaluation and characterization of any of the elementary lesions [21].

Currently, several groups are looking to develop novel tools to automatically detect significant lesions in VCE, though only a few deal with the detection of angioectasias $[14,22]$. Texture $[23]$ and color $[24,25]$ extraction algorithms are usually used as feature sources of classifiers. Regarding color, angioectasias seem to have a better characterization in the CIELab than in the red, green, blue (RGB) color spaces [25]. In this line of thought, we worked with the Center for MicroElectroMechanics Systems (CMEMS-Uminho) to develop a novel algorithm to identify angioectasias in SB [26].

The CMEMS-Uminho algorithm is the first to approach the transformation of the image according to the CIELab color system and to add a segmentation process. When compared to the methods already published to detect angioectasias in VCE static frames, the proposed sys- tem shows a better performance: sensitivity of $95.32 \%$, specificity of $94.75 \%$ and ROC area of $97.87 \%$ [26]. Even though these results are promising, as in other algorithms previously described, it demands realistic experimentation.

Therefore, we aimed to evaluate our algorithm overall performance using full-length VCE video, assess its diagnostic yield in clinical practice and impact on physician's performance.

\section{Methods}

\section{The CMEMS-Uminho Algorithm}

The algorithm developed at the CMEMS-Uminho, in University of Minho Engineering School, summarily consists in the transformation of the image according to the CIELab color system which has three parameters: L represents the brightness variation between black (0) and white (100); the components a and b represent the color opponent dimensions, where a sets the magenta color to positive values and the green color to negative values, and $b$ sets the yellow color to positive values and the blue color to negative values. This model is more uniform and its components have 

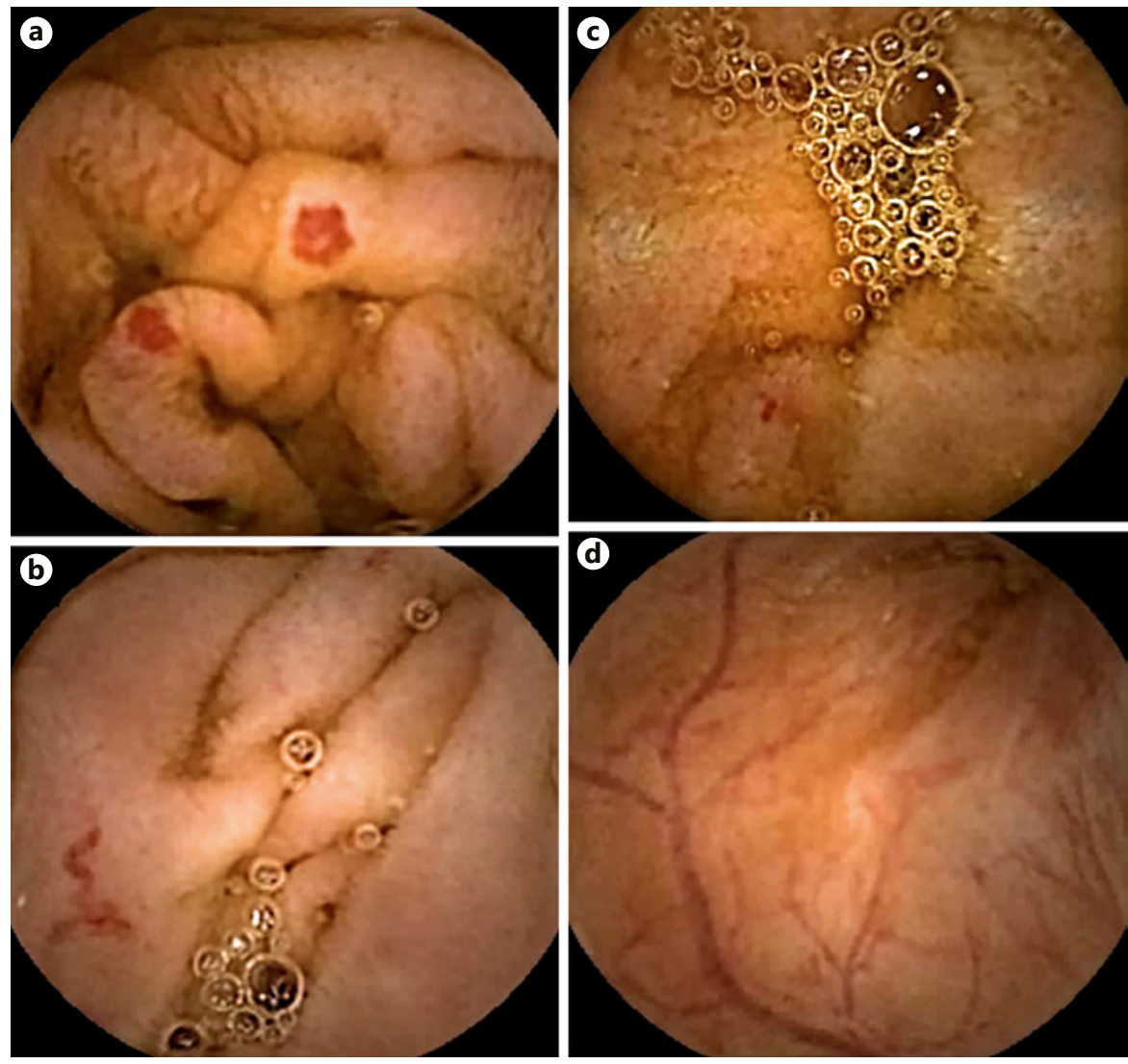

Fig. 2. Examples of frames from PillCam ${ }^{\circledR}$ software selected by the CMEMS-Uminho algorithm: true positive (a, b); false negative (c); false positive (d)

a less degree of correlation than the RGB System [27]. Angioectasias usually have a red color, so they will be highlighted in component a. As the length of the diameter increases, the possibility of bleeding and the rate of detection by CIELab color system also increases (Fig. 1).

Afterwards, the histogram of the component a is divided into two sections, where the one with the higher values is considered as the region with the lesion (angioectasia). This segmentation of the image is done using a method called expectation-maximization [24], where the parameters of both distributions are estimated in an iterative manner. The extraction of the characteristics is obtained based on histogram measures, namely the mean and variance of the two-color components ( $\mathrm{a}$ and $\mathrm{b}$ ) from both selected regions. The process of segmentation of the images allows a standardization of the color spaces, finding one that is complete enough to be able to define all the existing colors $[28,29]$.

The classification of the frame as normal or abnormal is done using supervised learning methods, in this case a multilayer perceptron [27], which is a specific type of a neural network.

Algorithm accuracy was previously attained with static images from PillCam ${ }^{\circledR}$ (Given, Israel) [26].

\section{Study Design and Data Collection}

Overall Performance of the CMEMS-Uminho Algorithm

Algorithm overall performance was determined using 54 fulllength VCE videos (39 PillCam ${ }^{\circledR}$ [Given, Israel] and 15 MiroCam ${ }^{\circledR}$ [IntroMedic, Korea]) with SB angioectasias, previously identified by an expert capsule endoscopist at the Gastroenterology Department of Braga Hospital.

VCE videos were downloaded from the original software, so the CMEMS-Uminho algorithm could be applied separately from the vendors' software. For each VCE, the algorithm provided a smaller video consisting of the grouping of frames selected. One frame automatically tagged by the algorithm and one selected by the expert had the same time code, thus the overall performance of the CMEMS-Uminho algorithm was defined by a positive concordance between a frame selected by the algorithm and the expert.

Clinical Performance of CMEMS-Uminho and the Impact on Physicians

To assess the usability of the CMEMS-Uminho algorithm in clinical practice, VCE recordings with SB angioectasias consecutively performed (2017-2018) in the Department of Gastroenterology of Hospital of Braga were evaluated, a total of $41 \mathrm{VCE}$ videos. Videos with blood and poor preparation were excluded. VCE procedures were performed according to a standardized protocol: clear liquid diet the day prior to VCE plus a 12-h fasting protocol. The recording device was set in the morning and removed in the late afternoon. Patients were allowed to drink fluids after $2 \mathrm{~h}$ and to have a light meal after $4 \mathrm{~h}$.

All VCE recordings were firstly interpreted by an expert capsule endoscopist (experience around 500 capsules procedures; physician 1), who proposed the clinical diagnosis of angioectasias
90

GE Port J Gastroenterol 2021;28:87-96 DOI: $10.1159 / 000510024$
Costa/Vieira/Pinto/Arroja/Leal/Mendes/ Gonçalves/Lima/Rolanda 

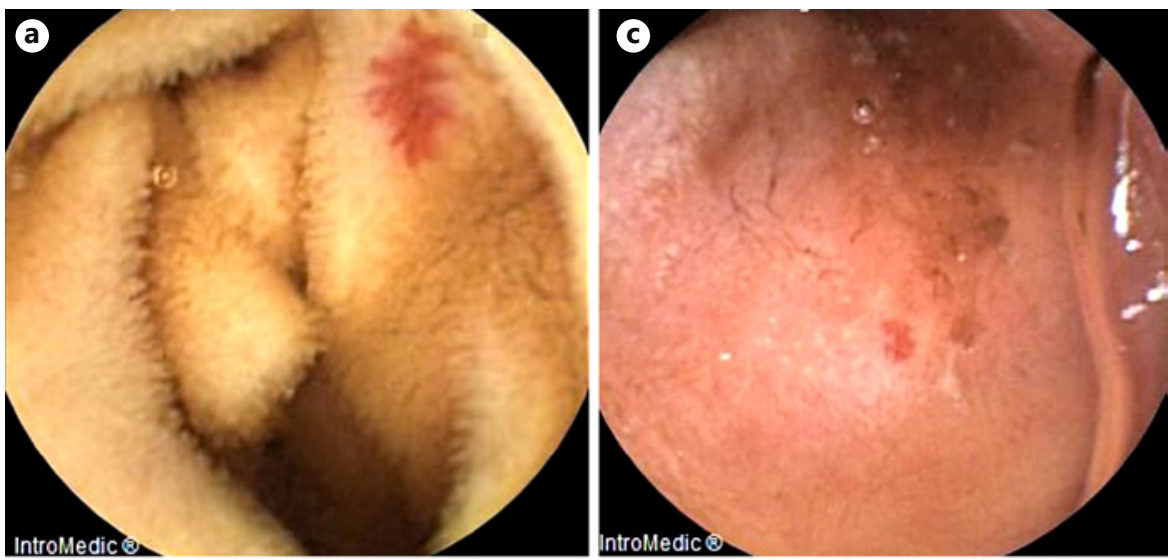

Fig. 3. Examples of frames from Miro$\mathrm{Cam}^{\circledR}$ software selected by the CMEMSUminho algorithm: true positive (a, b); false negative (c); false positive (d).
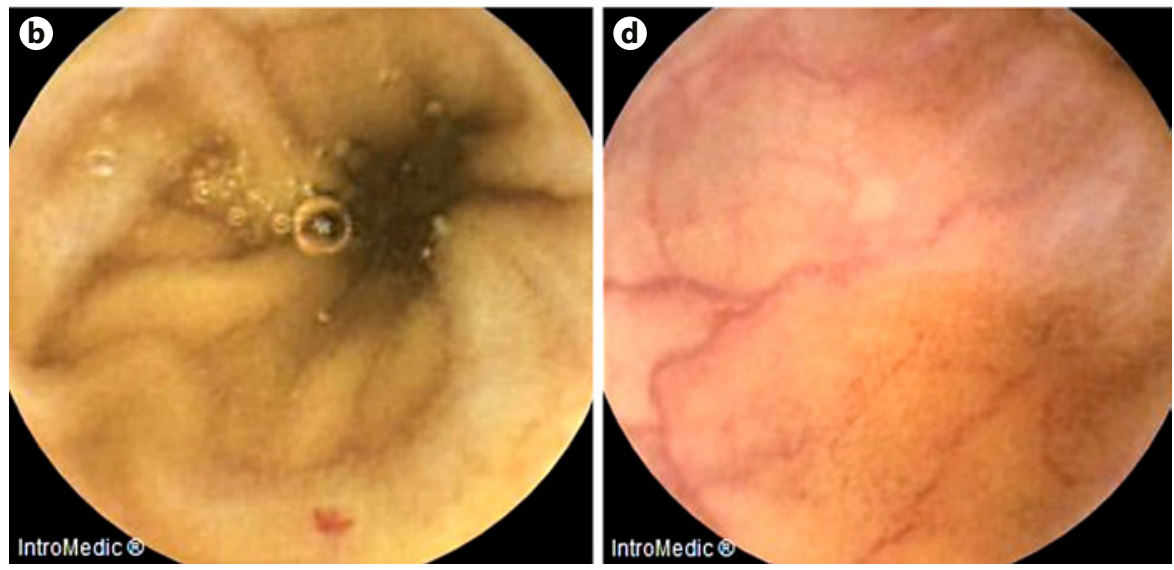

and also registered the anatomic landmarks, the clinically significant lesions, timing and speed viewing, and quality of SB cleansing. Only lesions in the SB were considered (those found in between the pylorus and the ileocecal valve as defined by the first duodenal and first colonic video frames, respectively).

Posteriorly, two gastroenterology trainees with different VCE reading experience (50 and 10 capsules procedures; physician 2 and 3 , respectively) were asked to review the VCE recordings and to register the data described above for physician 1. The SingleView mode of VCE was defined for all physicians. Each physician reviewed each VCE only once and without knowing the results from either one of the other physicians and before applying the algorithm.

VCE videos were downloaded from the original software. The CMEMS-Uminho algorithm was applied separately from the vendors' software and provided a smaller video consisting of the grouping of frames selected. All images tagged by the algorithm and physicians were reviewed by an independent capsule endoscopist (experience around $150 \mathrm{CE}$ ) that confirmed if the lesion selected was an angioectasia and evaluated the concordance between them.

We compared physicians' performance, regarding global detection rate (total number of angioectasias detected), detection rate per capsule (number of angioectasias tagged in each VCE), diagnostic yield (number of VCE with clinical diagnosis of angioectasias), true positive rate (TPR, number of lesions correctly identified as angioectasia in each VCE), viewing time, and speed.

CMEMS-Uminho Algorithm to Detect

Angioectasias in Capsule Endoscopy
At last, an analysis was also made to assess the performance of each physician together with the results of the algorithm. The purpose was to infer what would be the result of using the algorithm in a clinical practice as a complement to physicians' readings of VCEs.

The experimental protocol was submitted and approved by the Sub-commission of Life and Health Sciences, University of Minho, and Ethics Committee for Health of Braga Hospital.

\section{Statistical Analysis}

Statistical analysis was performed using Statistical Package for the Social Sciences (SPSS Inc ${ }^{\circledR}$, Chicago, IL, USA version 24.0 for Microsoft ${ }^{\circledR}$ Windows) and MATLAB ${ }^{\circledR}$ software (Mathworks ${ }^{\circledR}$; version 9.4). For the descriptive data, absolute frequencies $(n)$ and relative frequencies (\%) were used for qualitative variables; and medians and interquartile range were used for quantitative variables. Mean and standard deviations were also presented for quantitative variables, when required to facilitate data interpretation. Normal distribution was assessed by the skewness and kurtosis tests. Since this assumption was not observed, non-parametric statistics were used throughout the analysis.

The Mann-Whitney (U), Wilcoxon signed-rank (Z), and Friedman tests were performed to compare the distribution of continuous variables. The $\chi^{2}$, Fisher, and Cochran's $Q$ tests were assessed to test the association between categorical dichotomic variables. Results were considered statistically significant for a $p$ value below 0.05 . 


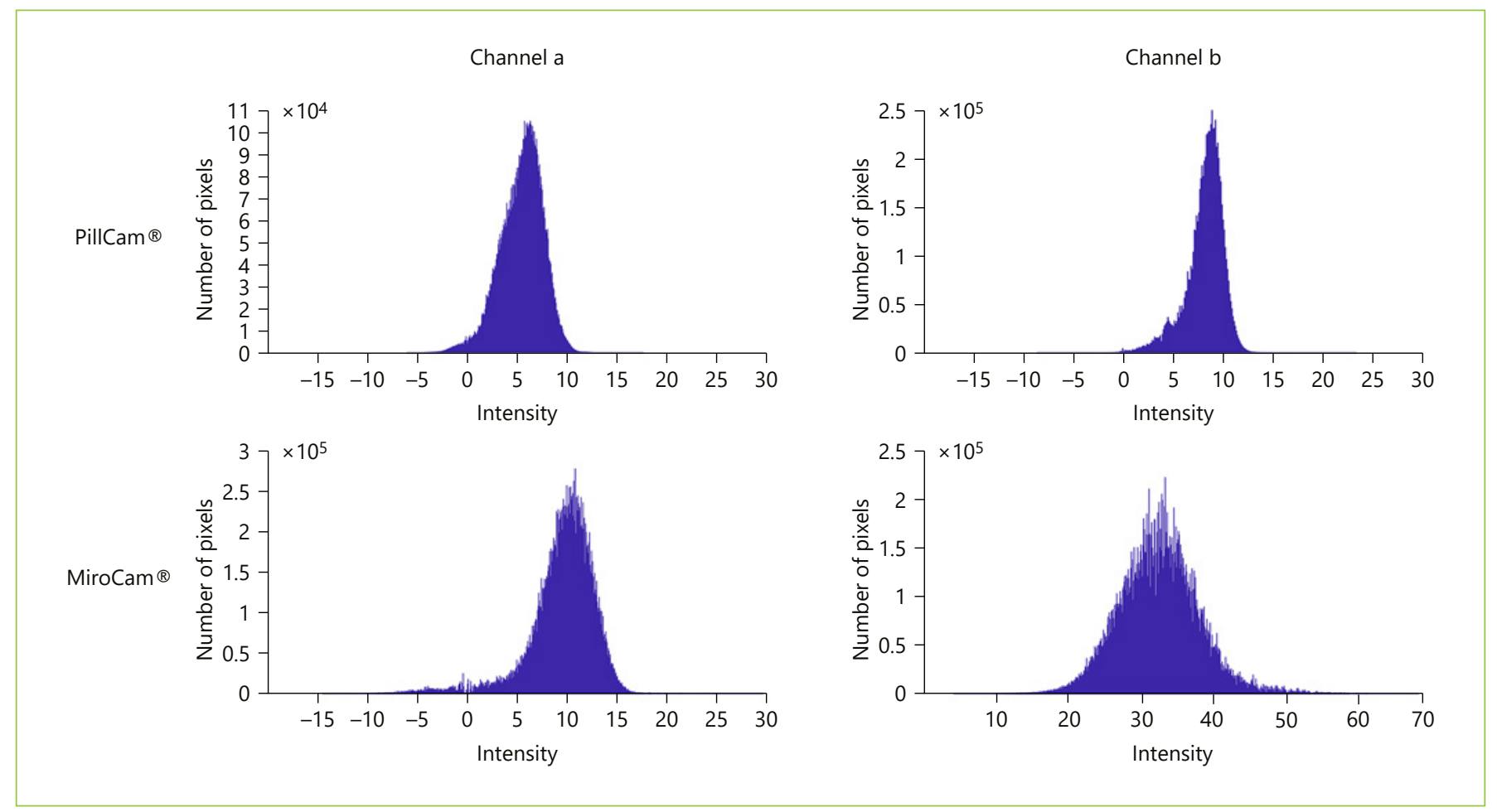

Fig. 4. Histograms with the color intensity of channels a and b, according to the VCE software.

\section{Results}

\section{Overall Performance of the CMEMS-Uminho}

Algorithm

In the evaluation of the full-length $54 \mathrm{VCE}$ recordings, the CMEMS-Uminho algorithm revealed a detection rate of $77.70 \%$ (identified 115 from a total of 148 angioectasias) (Fig. 2, 3). The lower performance significantly resulted from the failure of the algorithm in identifying punctiform angioectasias $(p<0.001)$.

No significant differences were observed in the algorithm performance between MiroCam ${ }^{\circledR}(74.2 \%)$ and Pill$\mathrm{Cam}^{\circledR}(78.6 \%)(p=0.598)$. Regarding the number of frames (and subsequently the size of the video performed by the software), the algorithm significantly selected more frames in VCEs from MiroCam ${ }^{\circledR}$ (mean $=886.06$ vs. $372.45 ; p=0.028$ ), suggesting a significant lower specificity. To further explore this data, 100 normal SB images were randomly selected from each software, and histograms with the color intensity of channels a and $\mathrm{b}$ were plotted. Both channel a $(p<0.00001)$ and $\mathrm{b}(p<0.00001)$ of Mirocam ${ }^{\circledR}$ frames significantly showed a higher intensity, with images displaying a more yellowish and reddish coloration, resulting in more false positives (Fig. 4).

\section{Clinical Performance of CMEMS-Uminho and the Impact on Physicians}

Regarding the 41 videos collected, 2 VCE examinations were excluded due to the presence of blood and 1 due to poor preparation. Thus, $38 \mathrm{VCE}$ recordings were considered for the analysis, and the CMEMS-Uminho algorithm revealed a diagnostic yield of $94.70 \%(n=36)$. The algorithm failed in 2 VCE examinations that displayed an isolated punctiform angioectasia. Nevertheless, it identified 3 angioectasias that were not identified by any of the physicians.

Concerning the global detection rate (Table 1), no significant differences were observed between physician 1 and $2(p=0.728)$, but both were significantly superior to physician $3(p<0.001)$. After addition of the algorithm analysis, each physician significantly improved the total number of angioectasias detected $(p<0.001)$ (Table 2$)$, and differences between physicians' performance were no longer noted $(p=0.108)$. Similar results were obtained in Detection Rate per capsule. Physician 1 and 2 did not significantly differ $(p=0.064)$, though both revealed greater detection rate than physician $3(p<0.001$ and $p=$ 0.029 , respectively) (Table 1 ). All physicians revealed significantly better results following algorithm application 
Table 1. Physicians' performance assessment

\begin{tabular}{|c|c|c|c|}
\hline & Reader 1 vs. reader 2 & Reader 1 vs. reader 3 & Reader 2 vs. reader 3 \\
\hline Global DR*, \% (n) & $\begin{array}{r}81.70(94) \text { vs. } 79.10(91) \\
p=0.728\end{array}$ & $\begin{array}{r}81.70(94) \text { vs. } 53.90(62) \\
p<0.001\end{array}$ & $\begin{array}{c}79.10(91) \text { vs. } 53.90(62) \\
p<0.001\end{array}$ \\
\hline $\begin{array}{l}\text { DR p/capsule**, } \% \\
\text { Mean }( \pm \text { SD) } \\
\text { Median }(\mathrm{IQR})\end{array}$ & $\begin{array}{c}90.06(15.7) \text { vs. } 76.70(34.8) \\
100(25.9) \text { vs. } 100(43.3) \\
p=0.064\end{array}$ & $\begin{array}{c}90.06(15.7) \text { vs. } 58.63(38.3) \\
100(25.9) \text { vs. } 53.57(66.7) \\
p=0.001\end{array}$ & $\begin{array}{c}76.70(34.8) \text { vs. } 58.63(38.3) \\
100(43.3) \text { vs. } 53.57(66.7) \\
p<0.029\end{array}$ \\
\hline Diagnostic yield* $\%(n)$ & $\begin{array}{r}100(38) \text { vs. } 86.8(33) \\
p=0.063\end{array}$ & $\begin{array}{r}100(38) \text { vs. } 78.9(30) \\
p=0.008\end{array}$ & $\begin{array}{c}86.8(33) \text { vs. } 78.9(30) \\
p=0.453\end{array}$ \\
\hline $\begin{array}{l}\text { TPR**, } \% \\
\quad \text { Mean }( \pm \mathrm{SD}) \\
\text { Median }(\mathrm{IQR})\end{array}$ & $\begin{array}{c}100(0)^{1} \text { vs. } 74.85(37.2) \\
100(0) \text { vs. } 100(42.5) \\
p<0.001\end{array}$ & $\begin{array}{c}100(0)^{1} \text { vs. } 51.78(35.4) \\
100(0) \text { vs. } 50(56.4) \\
p<0.001\end{array}$ & $\begin{array}{c}74.85(37.2) \text { vs. } 51.78(35.4) \\
100(42.5) \text { vs. } 50(56.4) \\
p=0.003\end{array}$ \\
\hline $\begin{array}{l}\text { Viewing speed**, fps } \\
\text { Mean }( \pm \mathrm{SD}) \\
\text { Median }(\mathrm{IQR})\end{array}$ & $\begin{array}{c}20(0)^{1} \text { vs. } 14.79(3.12) \\
20(0) \text { vs. } 15(2) \\
p<0.001\end{array}$ & $\begin{array}{c}20(0) \text { vs. } 12.63(1.32) \\
20(0) \text { vs. } 13(1) \\
p<0.001\end{array}$ & $\begin{array}{l}14.79(3.12) \text { vs. } 12.63(1.32) 15 \\
(2) \text { vs. } 13(1) \\
\quad p<0.001\end{array}$ \\
\hline
\end{tabular}

$\mathrm{DR}$, detection rate; fps, frames per second; TPR, true positive rate; SD, standard deviation; IQR, interquartile range. * Cochran's Q test was performed with $p<0.05$, thus McNemar tests with Bonferroni correction were performed and displayed in the table; ${ }^{* *}$ Friedman test was performed with $p<0.05$, thus Wilcoxon tests with Bonferroni were performed and displayed in the table. ${ }^{1}$ This value is a constant for this physician.

Table 2. Physicians' performance with and without the CMEMS-Uminho algorithm

\begin{tabular}{|c|c|c|c|}
\hline & Reader 1 vs. reader $1+\mathrm{A}$ & Reader 2 vs. reader $2+A$ & Reader 3 vs. reader $3+\mathrm{A}$ \\
\hline Global DR*, \% (n) & $\begin{array}{r}81.70(94) \text { vs. } 92.20(106) \\
p<0.001\end{array}$ & $\begin{array}{c}79.10 \text { (91) vs. } 95.70(110) \\
p<0.001\end{array}$ & $\begin{array}{c}53.90(62) \text { vs. } 89.6(103) \\
p<0.001\end{array}$ \\
\hline $\begin{array}{l}\text { DR p/capsule**, } \% \\
\text { Mean }( \pm S D)^{1}\end{array}$ & $\begin{array}{c}90.06(15.7) \text { vs. } 95.72(10.8) \\
\qquad p=0.012\end{array}$ & $\begin{array}{c}76.70(34.8) \text { vs. } 92.31(22.7) \\
p=0.004\end{array}$ & $\begin{array}{c}58.63(38.3) \text { vs. } 88.19(25.1) \\
p<0.001\end{array}$ \\
\hline Diagnostic yield*, \% (n) & $100(38)^{2}$ vs. - & $\begin{array}{r}86.8 \text { (33) vs. } 97.4(37) \\
p=0.125\end{array}$ & $\begin{array}{r}78.9(30) \text { vs. } 92.1(35) \\
\qquad p=0.063\end{array}$ \\
\hline
\end{tabular}

A, algorithm; $p$, $p$ value; SD, standard deviation. ${ }^{*}$ Wilcoxon test was performed; ${ }^{* *}$ Mann-Whitney test was performed; ${ }^{1}$ Mean and SDs were used to facilitate data interpretation; ${ }^{2}$ Video capsule endoscopy videos were selected according to the clinical diagnosis of angioectasias performed by Reader 1 .

(Table 2), and differences between them were diluted $(p=0.108)$.

With regard to diagnostic yield, only physician 1 detained significant superiority against physician 3 ( $p=$ 0.008) (Table 1). Physician 2 and 3 could improve their diagnostic yield, though without significance $(p=0.125$ and $p=0.063$, respectively) (Table 2). Nevertheless, differences between readers' performance were no longer detected following algorithm inclusion $(p=0.097)$. 
At last, physician 1 revealed significantly higher TPR than physicians $2(p<0.001)$ and $3(p<0.001)$. Physician 2 also displayed a better result when compared to physician 3 ( $p=0.003$ ) (Table 2). Similar results were observed regarding VCE viewing speed and time. Reader 1 was faster (in speed and time) than the other physicians $(p<$ 0.001 ). Physician 3 was also significantly slower than physician $2(p<0.001)$, but no significant differences were revealed between the time spent in VCE viewing.

\section{Discussion}

SB capsule endoscopy is currently the first line of investigation of OGIB and an important diagnostic tool in several other diseases [2-4, 30]. Despite its high diagnostic yield, the true sensitivity of VCE is difficult to determine due to the lack of an adequate gold standard [6]. Furthermore, the reading time and interpretation of video capsule data is very time consuming, given that, in total more than 50,000 images have to be reviewed, which contributes to the high cost of a VCE examination [24]. Thus, a computer aided diagnosis (CAD) tool to help the physicians to evaluate VCE exams faster and more accurately is an important technical challenge and an excellent economic opportunity.

The algorithm developed at the CMEMS-Uminho showed greater performance to detect angioectasias than other methods previously published [26]. To overcome the limitation inherent to most studies that examine CAD tools, we evaluated CMEMS-Uminho algorithm performance in full-length VCE recordings. As expected, angioectasias detection rate diminished, but a satisfactory performance was maintained (77.70\%). This result was still superior to suspected blood indicator, which detains a sensitivity of $55 \%$ to detect potentially bleeding lesions [31].

Interestingly, our software mostly failed to identify punctiform angioectasias (reduced area/volume). Considering the positive correlation between severity and lesion extension $[25,29]$, the algorithm sustained a great detection rate of lesions with higher probability of bleeding. Even so, in the future we can "teach" the algorithm in the training stage to enhance its ability to recognize punctiform angioectasias.

This is the first study to assess different VCE systems. Most available tools to enhance VCE diagnostic yield were developed using Given Imaging ${ }^{\circledR}$, though other systems have been widely used in the clinical practice. CMEMS-Uminho algorithm performance did not differ between both endoscopic capsules evaluated. Even though specificity was not possible to calculate, data suggests that our algorithm displays a lower specificity in VCE recordings from Mirocam ${ }^{\circledR}$, since the number of frames selected by the algorithm was significantly higher (at the expense of a heavier video). This occurs as a consequence of Mirocam ${ }^{\circledR}$ frames displaying a more yellowish and reddish coloration, resulting in more false positives. Since the algorithm was trained with PillCam ${ }^{\circledR}$ images [26], it possibly makes sense to change the segmentation method so that the CMEMS-Uminho algorithm can better separate the tissue from the angioectasias amongst the normal tissue. This can be done using a segmentation method that uses both channel a and channel $\mathrm{b}$; or the inclusion of a normalization factor that takes into account the overall coloration of each image. Despite this, the algorithm proved to be able to detect angioectasias in both systems, which allows to infer that following a training with images of both capsules systems, the algorithm can increase its diagnostic performance.

The CMEMS-Uminho algorithm revealed an excellent diagnostic yield (94.70\%), though interpretation should be carefully done due to our small sample. Notwithstanding, our data may be comparable or even better than previously discussed tools [14-18]. Arieira et al. [19] revealed an overall diagnostic yield of $42 \%$ for Top 100 , though angioectasia was diagnosed in $86.7 \%$. Boal Carvalho et al. [32] also showed that FICE 1 displayed a significantly higher diagnostic yield than white light ( 55 vs. $42 \%$ ), particularly to identify angioectasias. Moreover, the $2 \mathrm{VCE}$ examinations that the algorithm failed to identify any lesion displayed an isolated punctiform angioectasia. Hence, training the algorithm not only can possibly improve algorithm overall performance, but also its diagnostic yield.

The main purpose of these computerized tools is to enhance physicians' performance in the clinical practice. Zheng et al. [6]. revealed that the detection rate of angioectasias by physicians is disappointing, since only $69 \%$ of these lesions were detected. In our study, the most experienced physician was faster (in speed and time) to review $\mathrm{CE}$ recordings, while revealing greater diagnostic yield and TPR than both trainees, but his global detection rate and detection rate per capsule were not superior to the most experienced trainee. Even though our results should not be inferred to the population due to our sample, our data is comparable to the literature. Experienced capsule endoscopists are not necessarily better interpreters than their less-experienced counterparts $[6,33]$. Therefore, experience should not serve as a pass to review studies more efficiently.
Costa/Vieira/Pinto/Arroja/Leal/Mendes/ Gonçalves/Lima/Rolanda 
Remarkably, the CMEMS-Uminho algorithm might enhance physicians' performance in the clinical practice. With the addition of the algorithm analysis, it was possible to infer what would be the result of using the algorithm in a clinical practice as a complement to physicians' readings of VCEs. All readers significantly improved their global detection rate and detection rate per capsule. Moreover, significant differences between them were no longer observed. Consequently, physicians with different experiences in VCE examinations may achieve similar clinical performance, which may also suggest a role of the CMEMS-Uminho algorithm in the learning process of the Gastroenterology trainee.

The main limitation of this study was sample size and the number of physicians enrolled in the study. Also, more than one study-independent capsule endoscopist should have been used to achieve a more accurate algorithm and readers' performance data. In the future, we intend to improve this tool in order to overcome the exposed failures and to develop an improved version of the software, where other lesions can be simultaneously detected.

In conclusion, this new computerized tool displayed an excellent diagnostic yield and improved physicians' performance in clinical practice. Multicenter and randomized controlled trials are important to validate our findings.

\section{Statement of Ethics}

We declare that this study was conducted in accordance with the Declaration of Helsinki, and it was submitted and approved by the Sub-Commission of Life and Health Sciences, University of Minho, and Ethics Committee for Health of Braga Hospital.

\section{Conflict of Interest Statement}

The authors have no conflicts (financial, professional, or personal) to declare.

\section{Funding Sources}

The authors have no fund or financial relationships to declare.

\section{Author Contributions}

Dalila Costa, Pedro Vieira, and Catarina Pinto performed the literature search, collected and analyzed the data, and wrote the paper. Bruno Arroja, Tiago Leal, and Sofia Mendes contributed with data collection and revised the writing of the paper. Raquel Gonçalves, Carlos Lima, and Carla Rolanda contributed to study concept and design, analysis and interpretation of data and revised the writing of the paper. All authors approved the final manuscript.

\section{References}

1 Iddan G, Meron G, Glukhovsky A, Swain P. Wireless capsule endoscopy. Nature. 2000 May;405(6785):417.

2 Pennazio M, Spada C, Eliakim R, Keuchel M, May A, Mulder CJ, et al. Small-bowel capsule endoscopy and device-assisted enteroscopy for diagnosis and treatment of small-bowel disorders: European Society of Gastrointestinal Endoscopy (ESGE) Clinical Guideline. Endoscopy. 2015 Apr;47(4):352-76.

3 Gerson LB, Fidler JL, Cave DR, Leighton JA. ACG Clinical Guideline: Diagnosis and Management of Small Bowel Bleeding. Am J Gastroenterol. 2015 Sep;110(9):1265-87.

4 Enns RA, Hookey L, Armstrong D, Bernstein CN, Heitman SJ, Teshima C, et al. Clinical Practice Guidelines for the Use of Video Capsule Endoscopy. Gastroenterology. 2017 Feb; 152(3):497-514.

5 Swain P. Wireless capsule endoscopy. Gut. 2003; 52(90004): 48iv-50. https://doi. org/10.1136/gut.52.suppl_4.iv48.

6 Zheng Y, Hawkins L, Wolff J, Goloubeva O, Goldberg E. Detection of lesions during capsule endoscopy: physician performance is disappointing. Am J Gastroenterol. 2012 Apr; 107(4):554-60

7 Wang A, Banerjee S, Barth BA, Bhat YM, Chauhan S, Gottlieb KT, et al.; ASGE Tech- nology Committee. Wireless capsule endoscopy. Gastrointest Endosc. 2013 Dec;78(6): 805-15.

8 Ciuti G, Menciassi A, Dario P. Capsule endoscopy: from current achievements to open challenges. IEEE Rev Biomed Eng. 2011;4:5972.

9 Bourreille A, Ignjatovic A, Aabakken L, Loftus EV Jr, Eliakim R, Pennazio M, et al.; World Organisation of Digestive Endoscopy (OMED) and the European Crohn's and Colitis Organisation (ECCO). Role of small-bowel endoscopy in the management of patients with inflammatory bowel disease: an international OMED-ECCO consensus. Endoscopy. 2009 Jul;41(7):618-37.

10 Appleyard M, Fireman Z, Glukhovsky A, Jacob H, Shreiver R, Kadirkamanathan S, et al. A randomized trial comparing wireless capsule endoscopy with push enteroscopy for the detection of small-bowel lesions. Gastroenterology. 2000 Dec;119(6):1431-8.

11 Wolff J, Uradomo L, Goldberg E. Wireless Capsule Endoscopy Practice Makes Perfect? A Survey of Capsule Endoscopy Viewing Practices in the United States. Gastrointest Endosc. 2009;69(5):AB201.

12 Rondonotti E, Villa F, Mulder CJ, Jacobs MA, de Franchis R. Small bowel capsule endosco- py in 2007: indications, risks and limitations. World J Gastroenterol. 2007 Dec;13(46): 6140-9.

13 Regula J, Wronska E, Pachlewski J. Vascular lesions of the gastrointestinal tract. Best Pract Res Clin Gastroenterol. 2008;22(2):313-28.

14 Iakovidis DK, Koulaouzidis A. Software for enhanced video capsule endoscopy: challenges for essential progress. Nat Rev Gastroenterol Hepatol. 2015 Mar;12(3):172-86.

15 Buscaglia JM, Giday SA, Kantsevoy SV, Clarke JO, Magno P, Yong E, et al. Performance characteristics of the suspected blood indicator feature in capsule endoscopy according to indication for study. Clin Gastroenterol Hepatol. 2008 Mar;6(3):298301

16 D’Halluin PN, Delvaux M, Lapalus MG, Sacher-Huvelin S, Ben Soussan E, Heyries L, et al. Does the "Suspected Blood Indicator" improve the detection of bleeding lesions by capsule endoscopy? Gastrointest Endosc. 2005 Feb;61(2):243-9.

17 Imagawa $\mathrm{H}$, Oka S, Tanaka S, Noda I, Higashiyama M, Sanomura Y, et al. Improved visibility of lesions of the small intestine via capsule endoscopy with computed virtual chromoendoscopy. Gastrointest Endosc. 2011 Feb;73(2):299-306. 
18 Cotter J, Magalhães J, de Castro FD, Barbosa M, Carvalho PB, Leite S, et al. Virtual chromoendoscopy in small bowel capsule endoscopy: new light or a cast of shadow? World J Gastrointest Endosc. 2014 Aug;6(8):359-65.

19 Arieira C, Monteiro S, Dias de Castro F, Boal Carvalho P, Rosa B, Moreira MJ, et al. Capsule endoscopy: is the software TOP 100 a reliable tool in suspected small bowel bleeding? Dig Liver Dis. 2019 Dec;51(12):1661-4.

20 Ryu C, Song J, Lee M, Shim C. Mo1670 Does Capsule Endoscopy With Alice Improves Visibility of Small Bowel Lesions? Gastrointest Endosc. 2013;77(5):AB466.

21 Ribeiro da Silva J, Pinho R, Rodrigues A, Ponte A, Rodrigues J, Sousa M, et al. Evaluation of the Usefulness of Virtual Chromoendoscopy with Different Color Modes in the MiroCam ${ }^{\circledR}$ System for Characterization of Small Bowel Lesions. GE Port J Gastroenterol. 2018 Sep;25(5):222-9.

22 Iakovidis D, Koulaouzidis A. Automatic lesion detection in wireless capsule endoscopy: A simple solution for a complex problem. IEEE International Conference on Image Processing (ICIP). 2014. https://doi. org/10.1109/ICIP.2014.7025453.
23 Szczypiński PM, Sriram RD, Sriram PV, Reddy DN. A model of deformable rings for interpretation of wireless capsule endoscopic videos. Med Image Anal. 2009 Apr;13(2):31224.

24 Vieira P, Ramos J, Barbosa D, Roupar D, Silva C, Correia H, et al. Segmentation of small bowel tumor tissue in capsule endoscopy images by using the MAP algorithm. Annual International Conference of the IEEE Engineering in Medicine and Biology Society. 2012. https://doi.org/10.1109/EMBC.2012.6346846.

25 Vieira P, Goncalves B, Goncalves C, Lima C. Segmentation of angiodysplasia lesions in WCE images using a MAP approach with Markov Random Fields. 38th Annual International Conference of the IEEE Engineering in Medicine and Biology Society (EMBC). 2016.

26 Vieira PM, Silva CP, Costa D, Vaz IF, Rolanda C, Lima CS. Automatic Segmentation and Detection of Small Bowel Angioectasias in WCE Images. Ann Biomed Eng. 2019 Jun; 47(6):1446-62.

27 Carson C, Belongie S, Greenspan H, Malik J. Blobworld: image segmentation using expectation-maximization and its application to image querying. IEEE Trans Pattern Anal Mach Intell. 2002;24(8):1026-38.
28 Glass P, Cheung E, Sitti M. A legged anchoring mechanism for capsule endoscopes using micropatterned adhesives. IEEE Trans Biomed Eng. 2008 Dec;55(12):2759-67.

29 McLaren K. XIII-The Development of the CIE $1976\left(L^{*} a^{*} b^{*}\right)$ Uniform Color Space and Color-difference Formula. J Soc Dyers Colour. 2008;92(9):338-41.

30 Rosa B, Cotter J. Current Clinical Indications for Small Bowel Capsule Endoscopy. Acta Med Port. 2015 Sep-Oct;28(5):632-9.

31 Yung DE, Sykes C, Koulaouzidis A. The validity of suspected blood indicator software in capsule endoscopy: a systematic review and meta-analysis. Expert Rev Gastroenterol Hepatol. 2017 Jan;11(1):43-51.

32 Boal Carvalho P, Magalhães J, Dias de Castro F, Gonçalves TC, Rosa B, Moreira MJ, et al. Virtual chromoendoscopy improves the diagnostic yield of small bowel capsule endoscopy in obscure gastrointestinal bleeding. Dig Liver Dis. 2016 Feb;48(2):172-5.

33 Postgate AJ, Fitzpatrick A, Basett P, Fraser C Polyp detection and size estimation at capsule endoscopy-does experience improve accuracy? A prospective animal-model study. 2007. Gastrointest Endosc. 2007;65(5):AB316. 